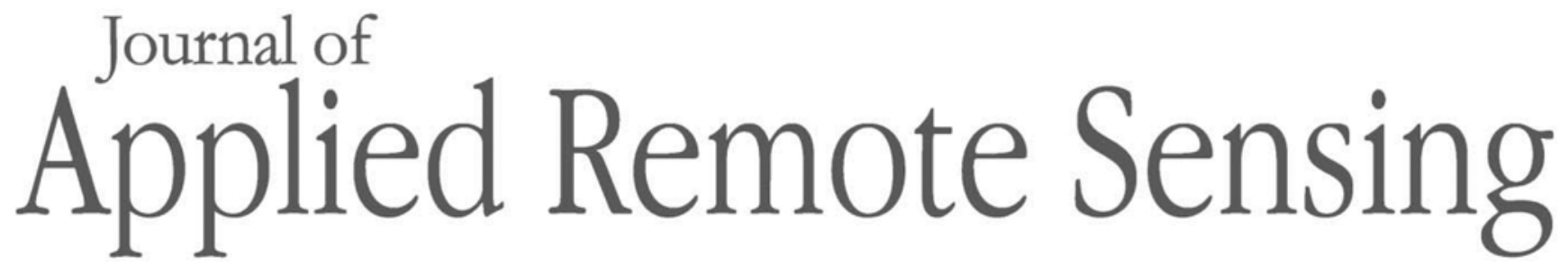

RemoteSensing.SPIEDigitalLibrary.org

\title{
Special Section Guest Editorial: Advances in Remote Sensing for Air Quality Management
}

\author{
Barry Gross \\ Klaus Schäfer \\ Philippe Keckhut
}




\title{
Special Section Guest Editorial: Advances in Remote Sensing for Air Quality Management
}

\author{
Barry Gross, ${ }^{\text {a }}$ Klaus Schäfer, ${ }^{\mathrm{b}}$ and Philippe Keckhut ${ }^{\mathrm{c}}$ \\ ${ }^{a}$ City University of New York, 160 Convent Avenue, New York, New York, United States \\ ${ }^{\mathrm{b}}$ Atmospheric Physics Consultant, Garmisch-Partenkirchen, Germany \\ 'Institute Pierre Simon Laplace (IPSL), Laboratoire Atmosphères, Milieux, Observations \\ Spatiales (LATMOS), Guyancourt, France
}

Over the last 30 years or so, there has been a dramatic increase in anthropogenic activities that are leading to a significantly enhanced burden for both climate and health impacts on a global scale. While global climate change and the anthropogenic influences of excessive greenhouse gas emissions are given well deserved publicity, there are additional equally disturbing health impacts that have been traced to enhanced pollutant exposure that are far less reported. In particular, while the general population is generally aware of the most direct climate impacts, including more intense and frequent heat waves, sea level rise, extreme weather events, and severe storm intensification due to warming oceans, other health risks such as exposure to high concentrations of fine particulate matter (aerosols) and surface level ozone are generally less appreciated.

To monitor climate change impacts such as temperature and relative humidity trends at near surface levels, low cost high density networks are available, but surface sampling of fine particulate matter and ozone is far more expensive and existing networks are generally located only in heavily impacted areas. In addition, localized surface measurements alone are not sufficient to understand the general mechanisms of aerosol and ozone $\left(\mathrm{O}_{3}\right)$ formation and transport. For example, the majority of tropospheric ozone formation occurs during daytime when nitrogen oxides $\left(\mathrm{NO}_{\mathrm{x}}\right)$, carbon monoxide $(\mathrm{CO})$ and volatile organic compounds (VOCs) react with UV sunlight. While most $\mathrm{O}_{3}$ precursors, such as motor vehicle exhaust, industrial emissions, and chemical solvents, often originate in urban areas, winds can carry $\mathrm{NO}_{\mathrm{x}}$ hundreds of kilometers, causing ozone formation to occur in less populated regions as well. Therefore, spatial and temporal observations on both regional and global scale of specific precursors such as $\mathrm{NO}_{\mathrm{x}}$ are critical to understanding specific $\mathrm{O}_{3}$ exceedance events. Additionally, $\mathrm{O}_{3}$ chemistry and transport are complex and titration of $\mathrm{O}_{3}$ plays an important role during periods with less or no sunshine as well as atmospheric layering which collects $\mathrm{O}_{3}$ in residual layers contributes due to mixing to surface $\mathrm{O}_{3}$ concentrations.

In addition to ozone and gas precursors, fine particulate matter (PM25) is a significant health risk with strict National Air Quality Standards (NAAQS) applied to exposure levels on an hourly, daily, and annual basis. Besides local emission sources resulting in both primary and secondary aerosol formation, strong contributions to particulate levels can occur due to transported aerosols such as biomass burning aerosols from wildfires as well as dust particulates that can travel over large distances and mix down into the tropospheric boundary layer.

Satellite remote sensing is the most critical component needed to provide the regional and global scale data for better understanding of atmospheric pollution processes and the first steps to provide forecasts and potential mitigation strategies.

To retrieve gases such as $\mathrm{NO}_{2}$ and $\mathrm{O}_{3}$ from space, satellites need to apply spectral differential absorption techniques and existing mature satellites, such as the Ozone Monitoring Instrument (OMI), using a visible/ultraviolet spectrometer aboard the NASA Aura spacecraft. Recent advances in technology have resulted in the recently launched TROPOMI satellite from the European Space Agency (ESA), which gives high resolution $\mathrm{NO}_{2}$ and tropospheric $\mathrm{O}_{3}$ as well as $\mathrm{CO}, \mathrm{CH}_{4}, \mathrm{SO}_{2}$ and absorbing aerosols. Even more exciting, unlike the existing polar orbiting instruments, the future launch (2020) of the Geostationary TEMPO (Tropospheric Emissions: Monitoring Pollution) mission will allow us to monitor major air pollutants across the North American continent every daylight hour at high spatial resolution.

For aerosol retrieval, until recently, we were generally restricted to mature polar orbiting satellites such as NASA MODIS. Existing geostationary satellites, such as NOAA GOES, 
were not capable of accurate aerosol optical depth retrieval (AOD), but with the recently launched GOES-16 in July 2017, we are now able to extract AOD retrievals at $4 \mathrm{~km}$ resolution at 5-minute temporal sampling. Besides quantitative AOD, qualitative dust and smoke masks, which can be used for aloft plume detection, are also maturing in the geostationary platforms.

However, the aerosol retrieval sensors described so far provide little in the way of classification and difficulties with land surface reflection, making direct intensity measurements more difficult to use over bright urban areas. While some aerosol properties can come from multiangle observations from sensors such as Multi-angle Imaging Spectroradiometer (MISR), polarization measurements are important for better differentiation between scattering and absorbing aerosols, which is critical when differentiating smoke and dust as well as removing land surface contaminations.

In this special section, we have tried to provide a good mix of papers. Some of our papers describe next-generation satellite sensors, some provide novel algorithmic approaches to optimize existing systems, some explore the accuracy of existing systems and some make use of observations to explore socio-economic consequences. In addition, we also have papers describing the use of active laser sensors for aerosol vertical profiling as well as an expository paper from HAQAST which describes the funding program used by NASA's Atmospheric Composition and Air Quality research programs and how this funding is being used to accelerate cooperative research and incorporate state and local air quality managers.

In the category of next-generation technologies, the paper by Diner et al. provides an overview of the special purpose Multi-Angle Imager for Aerosols (MAIA) instrument, which is in development and is designed to improve dramatically upon the existing MISR instrument in determining aerosol composition over urban areas by incorporating polarimetry and expanded spectral range with high spatial resolution. Besides improving the aerosol optical depth retrievals to specific components, methods are described to connect the observations directly to near-surface PM10, PM2.5, and speciated PM2.5. In a separate paper by Omar et al., the description and application of the NASA Plankton Aerosol, Cloud, ocean Ecosystem (PACE) mission, which uses dual multiangle polarimeters and can be used to provide key properties of aerosols, including effective particle radii, particle shapes refractive indices and single scattering albedos is described. Benefits include characterizing air masses for managing air quality, hazardous episodes of wildfire and volcanic emissions, and long range transport of pollution. This paper also describes efforts within NASA's applied sciences programs to establish a prelaunch early adopter program and outline communication strategies to engage the air quality user community.

In the category of new algorithm approaches, Hai Zhang et al. describe three different dust detection algorithms from the Suomi (NPP) Visible Infrared Imaging Radiometer Suite (VIIRS) instrument and explore performance metrics including accuracy, retrieval frequency, etc. Two complementary papers by Huang et al. and Chen et al. use multiple imagery from geostationary platforms together with complementary high resolution polar imagery to explore spatial temporal image fusion methods, which can result in high spatial resolution AOD retrievals useful for urban pollution observations.

In the category of satellite validation and evaluation, Yiwei Zhang et al. explore the performance of the OMPS instrument against a network of surface Brewer Ozone Spectrometers and compare performance with the TOMS Total Ozone Mapper. Diurnal and seasonal comparisons are made and quantitative assessment of OMPS improved performance is provided.

In the category of air management applications, which was funded by the HAQAST program and described in the paper by Tracey Holloway, the paper by Darynova et al. explores the usefulness of long-term tropospheric $\mathrm{NO}_{2}$ measurements from OMI to identify and quantify $\mathrm{NO}_{2}$ emission hot spots, trends, and seasonal variations over Kazakhstan. Both downward and upward trends are observed and their potential causes identified. Strong connections to emissions associated with electricity production are identified, and seasonal differences due to usage and different $\mathrm{NO}_{2}$ lifetimes are described. In a more global applications paper by Montgomery and Holloway, the complex relationship between satellite $\mathrm{NO}_{2}$ derived emissions and socio-economic production are explored.

Finally, the paper by Jin et al. describes the usefulness of fairly cheap ceilometers in providing important connections between surface level PM25 and optical attenuated backscatter, which can be used to provide the crucial link between surface PM25 and integrated optical depth. 
The authors describe special difficulties and the need to apply proper calibration and describe these efforts in detail.

The special guest editors and the JARS permanent editorial staff hope that this special section provides readers with a general feeling of existing work in remote sensing of both particulates and gases and that the connection between research and applications is far more involved and useful to health and socio-economic issues and that funding efforts to provide global studies are effective in bridging these gaps.

We would like to extend our appreciation to the authors who submitted their research for inclusion in this section. Our thanks also go to the efforts of the many reviewers for their critical comments in ensuring the highest quality in the research presented in this special section. 